\title{
EVIDÊNCIAS DE POLÍTICA NOVO-DESENVOLVIMENTISTA NO GOVERNO LULA (2003-2010): UMA ANÁLISE DO SETOR BANCÁRIO
}

\author{
EVIDENCE OF NEW DEVELOPMENTALIST POLICY IN THE LULA \\ GOVERNMENT (2003-2010): AN ANALYSIS OF THE BANKING SECTOR
}

\section{EVIDENCIAS DE POLÍTICA NUEVO-DESARROLLISTA EN EL GOBIERNO DE LULA (2003-2010): UN ANÁLISIS DEL SECTOR BANCARIO}

\author{
Darlan Christiano Kroth ${ }^{1}$ \\ http://orcid.org/0000-0003-2664-857X
}

Submissão: 06/05/2020 / Aceito: 20/07/2020 / Publicado: 20/01/2021.

\section{Resumo}

Este texto analisa a evolução do setor bancário, em especial do crédito, no Governo Lula (2003 a 2010), e avalia em que medida as políticas econômicas realizadas no setor se aderem ao referencial Novo-Desenvolvimentista. Para tanto, realizaram-se pesquisas bibliográfica e documental sobre literatura novo-desenvolvimentista e sobre economia bancária, acessando relatórios do Banco Central do Brasil e dados de crédito do Sistema de Informações do Banco Central. A análise demonstrou que o Governo Lula representou um ponto de inflexão para o setor, pois os bancos ampliaram significativamente o volume de crédito, se comparado ao histórico do segmento. Como principais fatores que explicam essa evolução, tem-se: a estabilidade macroeconômica, as reformas jurídicas e institucionais e os fatores microeconômicos. Avaliou-se que esses fatores refletiram ações intencionais de política econômica do governo, determinantes para criar um ambiente institucional mais propenso ao crédito. Entre as ações específicas estão: a ampliação do uso dos bancos públicos (BB, CEF e BNDES) por meio de crédito direcionado para atividades econômicas estratégicas, estimulando a competição no setor, medidas macroprudenciais e legais, como regulamentação do crédito consignado, e a lei que possibilita alienação fiduciária para imóveis. Por fim, verificou-se que essas políticas convergem com os preceitos defendidos pelo Novo-Desenvolvimentismo.

Palavras-Chave: Economia brasileira. Novo-Desenvolvimentismo. Bancos. Crédito.

\begin{abstract}
This paper analyzes the banking sector evolution, especially credit, during the Lula Government (2003 to 2010), evaluating to what extent the economic policies carried out adhere to the New Developmentalism framework. Therefore, bibliographic and documentary research was carried out regarding the New Developmentalist and the Banking Economics literatures, accessing reports from the Central Bank of Brazil and credit data from its Information System. The analysis showed that the Lula government represented a turning point for the sector, as the banks significantly increased the volume of credit, compared to
\end{abstract}

${ }^{1}$ Professor da Universidade Federal da Fronteira Sul (UFFS), campus Chapecó-SC. E-mail: dckroth@uffs.edu.br. 
the segment history. This evolution is mostly explained by these factors: macroeconomic stability, legal and institutional reforms, and microeconomic factors. Such factors were considered to reflect intentional government economic policy actions, which were decisive in creating an institutional environment more prone to credit. Among the specific governmental actions in the sector there are: the expansion of the use of public banks (BB, $\mathrm{CEF}$, and BNDES) by means of credit geared to strategic sectors, stimulating the competition in the sector, and macroprudential and legal measures, such as the regulation of payroll loans and the chattel mortgage law for real estate. Finally, the alignment of such policies with the New Developmentalist precepts is confirmed.

Keywords: Brazilian economy. New Developmentalism. Banks. Credit.

\section{Resumen}

Este trabajo analiza la evolución del sector bancario, especialmente de crédito, en el Gobierno de Lula (2003 a 2010), y evalúa si las políticas económicas realizadas en el sector se adhieren al marco nuevo-desarrollista. Para tanto, se hizo una investigación bibliográfica y documental sobre literatura del nuevo-desarrollismo y de economía bancaria, accediendo a información del Banco Central de Brasil y a datos crediticios del Sistema de Información del Banco Central. El análisis mostró que el Gobierno de Lula representó inflexión para el sector, ya que los bancos aumentaron significativamente el volumen de crédito, en comparación con la historia del sector. Los principales factores que explican eso son: estabilidad macroeconómica, reformas legales e institucionales y factores microeconómicos. Tales factores reflejan acciones intencionales de políticas gubernamentales, fundamentales para crear entorno institucional hacia el crédito. Entre las acciones específicas del gobierno en el sector se encuentran: la expansión del uso de los bancos públicos (BB, CEF y BNDES) mediante créditos dirigidos a actividades económicas estratégicas, estimulando la competencia en el sector, medidas macroprudenciales y legales, como la regulación de préstamos de nómina y la ley que permite la cesión fiduciaria de bienes raíces. Finalmente, se descubrió que esas políticas convergen con el Nuevo-Desarrollismo.

Palabras clave: Economía brasileña. Nuevo-Desarrollismo. Bancos. Crédito.

\section{INTRODUÇÃO}

O Governo Lula pode ser considerado como um ponto de inflexão para o setor bancário brasileiro, na medida em que os bancos passam a vislumbrar um cenário de crescimento da renda e de estabilidade econômica do país, que induz uma mudança no seu perfil de atuação. A mudança mais significativa é o direcionamento de uma maior parcela de seu portfólio para operações de crédito, resultando em uma ampliação do estoque de crédito de quase duas vezes. Acostumados a ganhar dinheiro com aplicação em títulos públicos e a ampliar receita com a cobrança de tarifas, a nova conjuntura impõe a necessidade de 
empréstimos e inovação em produtos, principalmente para absorver a nova classe média que ascende (SANTANNA et al., 2009).

Alterações bruscas no setor bancário não são novidades no Brasil, o segmento passou por forte reestruturação nos anos 1990, provocada pela estabilidade econômica e por uma conjuntura macroeconômica recessiva. Como principais resultados dessa reestruturação, teve-se a concentração do setor, com redução significativa de bancos públicos estaduais, a entrada de bancos estrangeiros e a adequação patrimonial dos bancos ao Acordo de Basileia (PAULA, 1998; ROCHA, 2001; SALVIANO JR, 2004). Todas essas mudanças contribuíram de alguma forma para estimular investimentos em automação bancária e gerar uma maior solidez no sistema financeiro nacional. Essas mudanças, porém, não foram capazes de alterar uma marca negativa do setor: o racionamento de crédito. A relação crédito/PIB não ultrapassou o índice de $29 \%$, um patamar muito baixo quando comparado com outros países (SOARES, 2001; SOBRINHO, 2003).

Considerando esse cenário, o presente trabalho possui dois objetivos. O primeiro é avaliar quais os fatores contribuíram para determinar a ampliação do crédito no período de 2003 a 2010 no Brasil, período este que perpassa o Governo Lula. Essa análise se torna relevante ao se verificar que, por um lado, o crédito foi uma das principais variáveis de política econômica do Governo, principalmente no quesito consumo, contribuindo, assim, para a expansão econômica do país. Por outro lado, ao passo que a economia mundial passa por uma crise financeira muito forte em 2008, os seus efeitos são abrandados no setor bancário brasileiro, em virtude das medidas governamentais de suporte que foram adotadas (NAPOLITANO, 2009; BARBOSA; SOUZA, 2010).

O segundo objetivo é avaliar em que medida os fatores que explicam a expansão do crédito estão alinhados com a tese Novo-Desenvolvimentista. O Novo-Desenvolvimentismo pode ser definido, conforme Bresser-Pereira (2006), como um conjunto de instituições e de políticas orientadas para o desenvolvimento econômico do país. Os estudos desse referencial iniciaram em 2003 e vêm ganhando corpo na literatura de economia brasileira, na instância de retomar e aprofundar o debate sobre uma nova agenda de políticas para o desenvolvimento socioeconômico nacional.

Para atingir os objetivos propostos, o estudo lançou mão de pesquisa bibliográfica e documental, caracterizando-se como um estudo avaliativo e descritivo. Mais especificamente, no primeiro objetivo, realiza-se análise documental dos relatórios de 
economia bancária e crédito do Banco Central do Brasil (BACEN) dos anos de 2002 a $2011^{2}$ e de dados secundários sobre operações de crédito do Sistema de Informações do Banco Central (SISBACEN) para o período de 2002 a 2011 (BACEN, 2014). Para esse objetivo, também foram realizadas análises de estudos sobre o comportamento e desempenho da atividade bancária pela literatura especializada. Para o segundo objetivo, empreendeu-se a pesquisa bibliográfica sobre a literatura do novo-desenvolvimentismo.

No que diz respeito à organização deste texto, o trabalho é desenvolvido ao longo de mais quatro partes, sendo a primeira uma revisão do pensamento Novo-Desenvolvimentista e suas proposições ao sistema financeiro. Na sequência, avalia-se o comportamento do crédito bancário no período, em termos de análise descritiva e de proposição de fatores que explicam esse fenômeno. A terceira parte avalia a forma que o Governo Lula atuou no setor, tendo o objetivo de fazer pontes com o referencial Novo-Desenvolvimentista. A última parte é reservada para a conclusão.

\section{NOVO-DESENVOLVIMENTISMO E SISTEMA FINANCEIRO}

Inicialmente proposto por Bresser-Pereira (2003 e 2004) $)^{3}$ o NovoDesenvolvimentismo (ND) pode ser definido, segundo esse autor, como uma estratégia nacional de desenvolvimento para o país, objetivando crescimento sustentado com equidade social. A tese ganha novos contornos e disseminação na obra de Sicsú et al. (2005), na qual o ND é exposto como um projeto de desenvolvimento alternativo às políticas adotadas a partir dos anos 1990 (e aprofundadas em 1995), pautadas nas diretrizes do Consenso de Washington, as quais possuem como veia teórica o neoliberalismo (também denominado como ortodoxia convencional). Para os teóricos do ND, o receituário ortodoxo não possibilitou ao país alcançar taxas de crescimento sustentado e manteve sua fragilidade externa, como ficou evidenciado ao longo dos anos 1990 e início dos anos 2000 por meio das várias crises financeiras enfrentadas pela economia mundial.

\footnotetext{
${ }^{2}$ Os relatórios estão disponíveis no seguinte endereço: https://www.bcb.gov.br/publicacoes/relatorioeconomia bancaria/cronologicos. Acesso em: 03 jan. 2021.

${ }^{3}$ Em parceria com Yoshiaki Nakano, que sugere a denominação ND em 2003, conforme Bresser-Pereira (2006).
} 
Conforme exposto nas obras seminais citadas anteriormente, a proposta da ND se opõe radicalmente ao receituário neoliberal, propondo um projeto alternativo. Apesar de também defender estabilidade macroeconômica, diferencia-se por contemplar uma estabilidade mais abrangente, não apenas calcada no controle da inflação. Para BresserPereira (2006, p. 20-21), a estabilização macroeconômica consiste em uma "taxa de inflação sob controle e razoável pleno emprego". Em sua perspectiva, "O ND é mais ambicioso: quer controlar o déficit público e, mais do que isto, lograr uma poupança pública positiva, que financie, senão totalmente, grande parte dos necessários investimentos públicos”. Ainda dentro dessa concepção de estabilidade, pode-se incluir a busca pelo equilíbrio do balanço de pagamentos, visando a não dependência da poupança externa ${ }^{4}$.

Os fundamentos teóricos que embasam o projeto ND são amplos, conforme apontado por Sicsú et al. (2005), mas pode-se considerar que estão concentrados nas visões Keynesiana e Neo-Estruturalista da CEPAL. Da primeira, herda a visão de complementaridade entre Estado e Mercado. Para a tese ND, o Estado permanece com um papel estratégico e deve ser fortalecido para poder efetuar a política de desenvolvimento, porém seu papel agora não é o de produtor, mas o de regulador, agindo de forma complementar ao mercado e corrigindo falhas no funcionamento deste.

Nesse sentido, além de estimular a concorrência no mercado, o Estado contribuiria para gerar a estabilidade macroeconômica exposta anteriormente, favorecendo a redução de incertezas relativas à demanda futura, que seriam responsáveis por determinar investimentos na economia. Para obter esse duplo fortalecimento, seriam necessárias a realização de uma reforma da gestão pública, a introdução de um sistema tributário progressivo, a conformação de um sistema de financiamento, a implementação de uma política industrial que estimule a competitividade externa da indústria e a ampliação de investimentos em educação (BRESSER-PEREIRA, 2006).

Com relação à concepção Neo-Estruturalista, a qual incorpora o termo "desenvolvimentismo", o ND assume o que lhe é mais caro, a ideia de uma estratégia de desenvolvimento nacional para o país. Segundo Bielschowsky (1988), o desenvolvimentismo (ou "velho" desenvolvimentismo como vem sendo referido pelos teóricos do ND) pode ser conceituado como "o projeto de superação do subdesenvolvimento através da

\footnotetext{
${ }^{4}$ Os principais elementos teóricos do Novo-desenvolvimentismo estão reunidos em Bresser-Pereira et. al. (2016)
} 
industrialização integral, por meio do planejamento e decidido apoio estatal" (BIELSCHOWSKY, 1988, p. 22). Esse modelo de desenvolvimento que perdurou de 1930 a 1980 no Brasil foi responsável pela implantação da indústria brasileira, mas sofre críticas por ter adotado um modelo fechado (industrialização via processo de substituição de importações), que acabou contribuindo para a geração de inflação, concentração de renda e diminuição da produtividade dos fatores de produção ${ }^{5}$.

Para Bresser-Pereira (2004) e Sicsú et. al. (2005), são essas limitações que o ND pretende superar. O "novo" pode ser caracterizado como a superação dos principais limites do modelo Cepalino, adequando sua estratégia à nova realidade brasileira, não mais fechada, mas aberta. A maior abertura comercial deveria se dar via negociação com os diversos setores da economia. O protecionismo permaneceria, mas com outra natureza, seria um protecionismo na conta capital para garantir a administração da taxa de câmbio. Quanto à função do Estado, em seu novo papel, deixaria de ser um Estado produtor, passando a ser mais atuante na esfera da regulação e coordenação do mercado, no financiamento de investimentos produtivos e passaria a impor políticas voltadas ao progresso técnico.

Ainda dentro do escopo das ações que constituem o arcabouço ND, há um espaço privilegiado para o financiamento ${ }^{6}$. Nas palavras de Sicsú et al. (2007, p. 516), “o desenvolvimento de um país depende da geração de capacidade própria de inovação e financiamento". A preocupação com o financiamento se justifica na medida em que ele é uma condição necessária para a retomada do desenvolvimento econômico, e em virtude do financiamento ter se demonstrado um gargalo histórico da economia brasileira, para o qual foram levadas a cabo formas pouco adequadas para suprir sua falta, como financiamento inflacionário e/ou endividamento externo, o que gerou distorções macroeconômicas ${ }^{7}$.

Segundo Carvalho (2005), o Sistema Financeiro Brasileiro (SFB) no início dos anos 2000 mantinha ainda uma característica não funcional, isto é, o SFB não criava condições de financiamento adequado para a promoção do crescimento sustentável da economia. Essa não funcionalidade era caracterizada pelos seguintes aspectos: i) baixa relação crédito/PIB se comparado com outros países; ii) baixo volume de crédito para investimentos produtivos de

\footnotetext{
${ }^{5}$ Para uma visão comparativa entre desenvolvimentismo e novo-desenvolvimentismo, ver Mollo e Fonseca (2013).

${ }^{6}$ Financiamento é entendido aqui como a forma pela qual os fundos (poupança) são mobilizados e utilizados na economia. Nesses termos, o sistema financeiro e as instituições financeiras a que pertencem, como os bancos - objeto deste estudo -, fazem parte do modelo/sistema de financiamento de uma economia.

${ }^{7}$ Para uma análise crítica do financiamento brasileiro, ver Tavares (1983).
} 
longo prazo; e iii) custo elevado do capital - spread elevado. Esse lado negativo do SFB era contrastado com outro, no qual o SFB se apresentava sólido e competitivo. A característica antagônica do SFB - competitivo e disfuncional - foi se desenvolvendo ao longo do tempo, em virtude das condições conjunturais e institucionais da economia brasileira, tal como são os casos da alta inflação, existência de mecanismos de correção monetária e o desenvolvimento de um inovador mercado de dívida pública.

Considerando essa característica, o autor defende a necessidade de uma reforma no SFB visando a ampliar sua eficiência em termos de: i) direcionamento de recursos para o investimento privado; ii) redução do custo do dinheiro para empresas e consumidores; e iii) promoção do acesso de grupos de baixa renda a produtos e serviços financeiros. Para alcançar tais metas, propõe a criação de incentivos de mercado e a intervenção regulatória com o objetivo de induzir um comportamento "pró-crédito" por parte das instituições financeiras (CARVALHO, 2005).

Nesse sentido, o ND prioriza, dentro das ações do Estado, a promoção de um sistema financeiro funcional, entendido como a capacidade de o setor financeiro financiar o investimento produtivo do país. Nesse caso, há a necessidade de o Estado intervir no SFB a fim de proporcionar as mudanças sugeridas, tornando-o eficiente e adequado à promoção do desenvolvimento. Pode-se argumentar que, implícita nessa tese, está a proposta de fortalecer o sistema de financiamento público (BNDES e bancos oficiais), bem como estimular a atuação do Banco Central para desenvolver o setor financeiro, tornando-o mais seguro e propenso a financiar a economia produtiva.

Um dos estudos que buscou avaliar a adesão/aderência do Governo Lula às estratégias novo-desenvolvimentistas é o de Morais e Saad Filho (2011). Os autores demonstraram que até 2006 (primeiro mandato do presidente Lula) a política econômica esteve pautada no tripé macroeconômico da ortodoxia convencional (metas de inflação, câmbio flutuante e superávit primário). Após uma reavaliação dessa política em 2006, o Governo Lula passa a adotar um conjunto de medidas que os autores chamam de híbridas (uma mescla entre ortodoxia convencional e ações atreladas ao receituário ND). Dentre essas ações de cunho ND, estão: i) medidas temporárias de estímulo fiscal e monetário - dentro deste rol de políticas contém a ampliação do crédito para consumo e crédito imobiliário; ii) medidas para ampliação do desenvolvimento social, como mecanismos de transferência de renda e aumento real do 
salário mínimo; e iii) maior participação do Estado em investimentos e planejamento de longo prazo (lançamento do Programa de Aceleração do Crescimento - PAC) ${ }^{8}$.

Para Morais e Saad-Filho (2011), a implementação das políticas ND se deu de forma parcial e complementar, em que a motivação para implementação dessas políticas foi mais de caráter pragmático do que convicção do Governo. Os autores consideram ainda que, apesar dos dois conjuntos de políticas adotadas serem inconsistentes, acabaram dando resultado positivo em virtude da melhoria de indicadores externos, como expansão da economia mundial e da liderança (carisma) do presidente Lula em convergir forças políticas heterogêneas em seu governo, tudo isso aliado à melhoria de indicadores socioeconômicos.

\section{O DESEMPENHO DO SETOR BANCÁRIO NO GOVERNO LULA}

\section{O comportamento do crédito}

Conforme apontado na seção anterior, a oferta de crédito no Brasil foi por longo tempo muito restrita, evidenciada pela baixa relação crédito/PIB. Conforme Santanna et al. (2009), essa realidade poderia ser explicada pela aversão ao risco, em virtude da existência de insegurança jurídica e contábil do país, e pela preferência pela liquidez por parte dos bancos, que neste caso direcionavam seu portfólio para aquisição de títulos públicos. Poderse-ia adicionar um terceiro fator, relacionado à concentração do setor bancário brasileiro conforme dados do Banco Central (2013): em 1999, os 10 maiores bancos detinham mais de $80 \%$ do mercado, o que levou alguns estudos a apontar a existência de racionamento de crédito por parte dos bancos brasileiros (SOBRINHO, 2003).

Esse cenário começa a mudar a partir de 2003 quando o país inaugurou uma tendência de crescimento da renda, a qual teve um papel importante para reduzir as condições adversas ao crédito. Diante desse novo contexto, os bancos passam a ampliar o volume de empréstimos. Conforme dados expostos na Figura 1, o crédito total é ampliado em $188 \%$ nos

\footnotetext{
${ }^{8}$ Segundo Barbosa e Souza (2010), em nenhum momento, o Governo Lula aludiu essas políticas ao arcabouço ND. Essas ações estariam mais alinhadas a uma vertente "desenvolvimentista" dentro do Governo, sem refletir necessariamente uma escola de pensamento econômico específica.
} 
oito anos do Governo Lula, tendo uma taxa de crescimento anual média de $14,1 \%{ }^{9}$. Esse crescimento melhora a relação crédito/PIB, principal indicador utilizado na literatura para indicar desenvolvimento financeiro; o indicador não ultrapassou o patamar de $29 \%$ ao longo da década de 1990, mas chega a atingir 46,4\% em 2010.

Figura 1 - Evolução do volume de estoque de crédito (Oper. de Crédito, em R\$ bilhões) e participação percentual no PIB brasileiro (\% PIB) - 2000 a 2010.

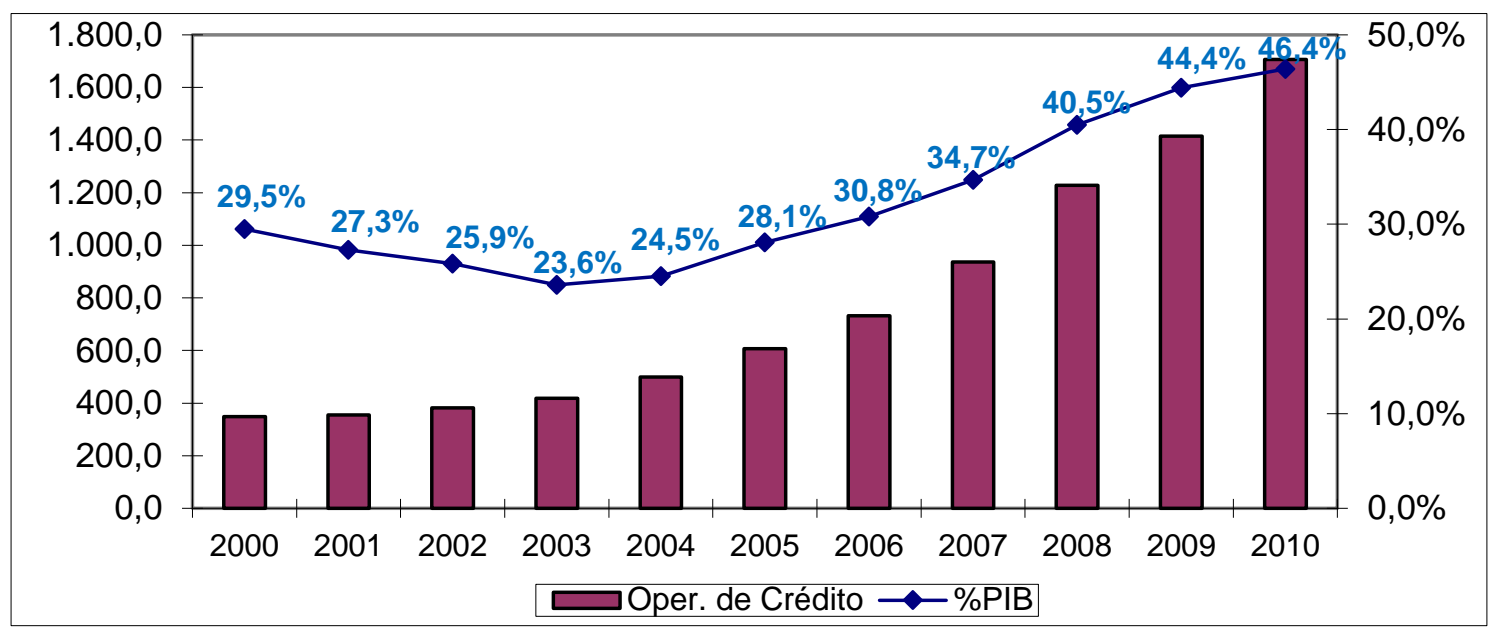

Fonte: SISBACEN/Banco Central do Brasil (2014)

O desempenho do crédito sofreu um pequeno revés (principalmente em termos de crédito empresarial) com a crise financeira mundial de 2008, em virtude da retração do mercado de crédito internacional, principal fonte de recursos livres para empresas até aquele ano. A ampliação do crédito direcionado, liderado pelo BNDES, amenizou essa situação após 2008. Apesar da significativa evolução do crédito, percebe-se pela Figura 2 que o país ainda está aquém das principais economias mundiais (Alemanha, EUA, Japão) e de economias emergentes (África do Sul, Chile, China e Coreia do Sul), no que concerne ao quesito crédito/PIB.

\footnotetext{
9 Os valores monetários apresentados na Figura 1 estão em termos nominais. As análises das variações percentuais consideraram esses valores deflacionados pelo IPCA, conforme podem ser observados na Tabela 1.
} 
Figura 2: Indicador de volume de operações de crédito/PIB para países selecionados 2009.

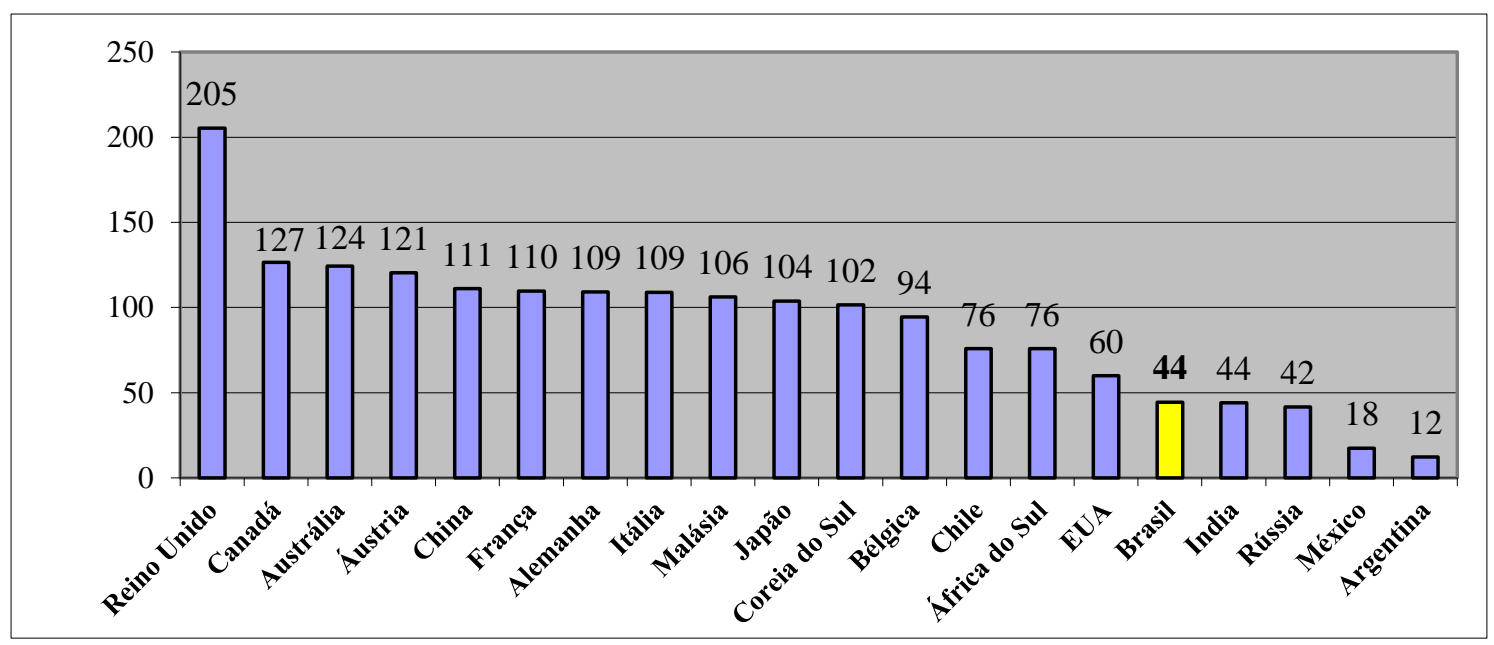

Fonte: Banco Mundial (2013)

A Tabela 1 expõe os dados da evolução do estoque de crédito por tipo de crédito. Pode-se verificar que a expansão do crédito foi liderada pelos recursos livres ${ }^{10}$ até o ano de 2008. Após esse ano, foi sustentada pelo crédito direcionado ${ }^{11}$. A oferta de recursos livres se expande $195 \%$ de dezembro de 2002 a dezembro de 2008, crescendo a uma taxa anual de 19,7\%. A partir de 2008, por efeito da crise, os recursos livres cresceram apenas $8,9 \%$, conforme destacado por Annibal et al., 2009.

De acordo com o Bacen (2013), o segmento de crédito com recursos livres que mais cresceu foi para Pessoa Física (PF), com crescimento de $317 \%$ contra um crescimento de 160\% para Pessoa Jurídica (PJ). As linhas de empréstimo para PF que mais se destacaram foram os créditos para consumo, principalmente o crédito consignado $(+880 \%)$ e o financiamento de veículos $(+226 \%)$. Em relação ao crédito para PJ, a linha de "financiamentos", representada pelo crédito de longo prazo, principalmente para investimento das empresas (aquisição de máquinas e equipamentos), ampliou-se em $140 \%$. Neste caso, a principal fonte de recursos foi o BNDES.

\footnotetext{
${ }^{10}$ Operações formalizadas com taxas de juros livremente pactuadas entre os mutuários e instituições financeiras, excluídas as operações de repasse do BNDES, ou quaisquer outras lastreadas em recursos compulsórios ou governamentais.

11 Operações realizadas com taxas ou recursos preestabelecidos em normas governamentais, destinadas, basicamente, aos setores rural, habitacional e de infraestrutura.
} 
Tabela 1 - Estoque de crédito no final de cada ano, por tipo de crédito 2003 a 2010 - Em R\$ bilhões

\begin{tabular}{llllllllll}
\hline Operação de Crédito & $\mathbf{2 0 0 2}$ & $\mathbf{2 0 0 3}$ & $\mathbf{2 0 0 4}$ & $\mathbf{2 0 0 5}$ & $\mathbf{2 0 0 6}$ & $\mathbf{2 0 0 7}$ & $\mathbf{2 0 0 8}$ & $\mathbf{2 0 0 9}$ & $\mathbf{2 0 1 0}$ \\
\hline 1. Recursos Direcionados & 241,4 & 240,5 & 256,4 & 272,2 & 300,4 & 341,1 & 418,8 & 502,6 & 589,8 \\
2. Recursos Livres & 347,8 & 378,1 & 450,8 & 540,6 & 638,8 & 822,4 & $1.024,6$ & $1.043,3$ & $1.116,0$ \\
2.1 Pessoa Jurídica & 213,5 & 229,5 & 262,8 & 285,2 & 333,8 & 427,7 & 560,9 & 529,8 & 556,0 \\
2.2 Pessoa Física & 134,2 & 148,6 & 188,0 & 255,4 & 305,1 & 394,6 & 463,7 & 513,6 & 560,0 \\
3. BNDES* & 132,7 & 134,8 & 156,0 & 166,2 & 178,2 & 198,9 & 246,2 & 309,3 & 357,8 \\
4. Habitacional** & 40,3 & 40,4 & 40,6 & 43,8 & 52,2 & 64,6 & 87,4 & 119,9 & 165,4 \\
5. Rural** & 50,4 & 64,8 & 73,9 & 78,7 & 90,1 & 102,8 & 120,2 & 116,2 & 122,9 \\
\hline 6. Total (=1+2) & 592,6 & 618,7 & 707,2 & 812,8 & 939,2 & $1.163,4$ & $1.443,4$ & $1.545,8$ & $1.705,8$ \\
\hline Cred/PIB & $\mathbf{2 5 , 7}$ & $\mathbf{2 4 , 0}$ & $\mathbf{2 4 , 5}$ & $\mathbf{2 8 , 1}$ & $\mathbf{3 0 , 8}$ & $\mathbf{3 4 , 7}$ & $\mathbf{4 0 , 5}$ & $\mathbf{4 4 , 4}$ & $\mathbf{4 6 , 4}$ \\
\hline
\end{tabular}

Fonte: SISBACEN/Banco Central do Brasil (2014). * Contempla Recursos direcionados. ** Contempla recursos livres e direcionados. Os valores foram deflacionados pelo IPCA.

O crédito direcionado apresentou evolução de $144 \%$, passando de $\mathrm{R} \$ 241,4$ bilhões em dezembro de 2002 para $\mathrm{R} \$ 590$ bilhões em dezembro de 2010, retratando uma taxa anual de crescimento de $11,8 \%$. Comparado com os recursos livres, o volume de crédito direcionado apresentou desempenho modesto até 2008, a partir daí ele se expande a um ritmo maior, ampliando em $41 \%$ seu estoque em dois anos. Os maiores responsáveis pela ampliação de recursos do crédito direcionado pós-2008 são os empréstimos do BNDES. O volume total despendido pelo banco no período foi ampliado $170 \%$, sendo $45,3 \%$ depois da crise financeira mundial.

A linha de crédito que apresentou maior expansão foi o crédito imobiliário, crescendo 310,4\%. O financiamento imobiliário pode ser considerado o carro-chefe da política econômica do Governo Lula, que possui um grande efeito multiplicador sobre a atividade econômica. Cabe destacar, conforme Bacen (2014), que em $201076 \%$ dos financiamentos imobiliários eram oriundos de bancos públicos, principalmente da Caixa Econômica Federal (CEF).

Fortemente articulado com a política social do Governo, esse empréstimo ganha impulso via inovações jurídicas para o segmento, como a alienação fiduciária e o patrimônio de afetação em virtude da Lei 10.931/2004. Um marco dessa linha de crédito foi o lançamento do Programa Minha Casa Minha Vida (PMCMV) em 2009, em âmbito do PAC, que direcionou recursos para famílias de baixa renda. A partir do lançamento desse programa, o volume de recursos salta de $\mathrm{R} \$ 119,9$ bilhões em 2009, para $\mathrm{R}$ \$ 165,4 bilhões em 2010, um crescimento de $38 \%$ em termos reais. 
Por fim, tem-se a linha de crédito rural, com expansão de cerca de 144\% nos oito anos do Governo Lula. Dentro dessa linha, estão contemplados os créditos para custeio, comercialização, investimento e agroindustrial, sendo que os recursos agroindustriais foram os que mais se expandiram (cerca de 400\%). Apesar de seu crescimento, o crédito rural perdeu participação no total do crédito, passando de $8,5 \%$ em dezembro de 2002 , para 7,2\% em dezembro de 2010. A perda de participação é decorrente de que os demais tipos de crédito se ampliaram em uma magnitude superior.

Com relação ao comportamento geral do crédito, aponta-se o fato de que, apesar de apresentar um crescimento significativo, os bancos privados mantiveram um perfil de empréstimo de curto prazo, enquanto o crédito de longo prazo ficou a cargo dos bancos públicos. Para Prates e Freitas (2013), essa configuração denota uma histórica "divisão de trabalho" no mercado bancário brasileiro, em que as instituições financeiras públicas se especializam na concessão de empréstimos de longo prazo, a partir de recursos direcionados, e as privadas priorizam o crédito de curto prazo, a partir de recursos próprios.

Além da evolução do crédito propriamente dito, deve-se mencionar que esse movimento veio acompanhado por outros três aspectos importantes: i) redução na taxa média de juros; ii) ampliação do prazo médio dos empréstimos; e iii) estabilidade nos níveis de inadimplência. Nesse sentido, pode-se argumentar que, além da quantidade, houve melhora na qualidade do crédito (BACEN, 2014). Conforme dados do BACEN (2014), a taxa de juros média cobrada pelos bancos passou de 56,7\% a.a. em 2003 para 39,7\% em 2010. O prazo médio passou de 219 dias/operação em 2003 para 381 dias/operação. Já a inadimplência não apresentou grandes mudanças, passando de 4,7\% em 2003 (2,9\% de PJ e 7,4\% de PF) para 4,5\% em 2010 (3,5\% de PJ e 5,7\% de PF).

Ao analisar os dados e estudos sobre o comportamento do crédito no período de 2002 a 2010, pode-se sintetizar que a melhoria dos indicadores expostos nos parágrafos anteriores foi devida à estabilidade macroeconômica do período (crescimento econômico com inflação estável) e ao avanço de vagas formais de emprego. Deve-se considerar também que as modalidades de crédito (principalmente o consignado) que apresentaram maiores garantias de pagamento foram determinantes para a redução da inadimplência e da taxa de juros verificadas, além de favorecer a ampliação dos prazos dos empréstimos. Ainda com relação à taxa de juros, o spread bancário caiu no período em cerca de 13,7\%, motivado principalmente pela redução dos custos administrativos - devido à maior automação 
bancária. Destaca-se, por fim, que os bancos públicos apresentaram maior flexibilidade para redução das margens líquidas (lucro), o que também contribuiu para a queda no spread (BANCO CENTRAL, 2014).

\section{Os fatores que estimularam a ampliação do crédito}

Esta seção aborda os fatores que ajudam a explicar o ponto de inflexão do setor bancário a partir de 2003 e a expansão do crédito no Brasil no período que abrange o Governo Lula, conforme evidenciado na seção anterior. Esta análise é relevante à medida que o perfil histórico de atuação dos bancos no Brasil sempre foi de caráter conservador e, portanto, de restrição do crédito, conforme demonstrado por Sobrinho (2003), bem como por Prates e Freitas (2013).

Para a realização da análise desta seção, foram considerados os Relatórios de Economia Bancária e Crédito do Banco Central, de 2002 a 2011, aliados a alguns trabalhos empíricos como os de Takeda e Bader (2005) e Martins et al. (2008). Dessa maneira, é possível apontar três conjuntos de fatores que contribuíram para a ampliação do crédito no Brasil: i) estabilidade macroeconômica; ii) reformas jurídicas e institucionais; e iii) fatores microeconômicos: inovação bancária, concorrência e posicionamento no mercado (market share). Analisa-se cada um deles em detalhes na sequência.

\section{i) Estabilidade macroeconômica:}

O período do mandato do presidente Lula apresentou um desempenho positivo da economia, evidenciado por vários indicadores macroeconômicos ${ }^{12}$. Após enfrentar instabilidade no início do Governo, influenciado pela incerteza gerada no período de eleições, o país entra em uma rota de crescimento, apresentando uma taxa anual média de 4,3\% (IPEA, 2014).

O desempenho econômico também foi reflexo da melhoria das contas externas. Nesses termos, houve um impulso das exportações estimulado pelo crescimento da economia

\footnotetext{
12 Ao comparar indicadores macroeconômicos, relativos a crescimento econômico, taxa de desemprego, taxa de inflação, saldo do balanço de pagamentos, reservas internacionais e criação de vagas formais de trabalho, entre os anos de 2002-2010, com período análogo anterior (1995-2001), verifica-se que a economia brasileira apresentou melhores indicadores no período de 2002-2010 (IPEA, 2014).
} 
mundial, resultando no acúmulo de reservas internacionais. As reservas apresentaram uma evolução de US\$ 33 bilhões para cerca de US\$ 290 bilhões. Esse desempenho proporcionou uma estabilidade externa (em termos de menor volatilidade na taxa de câmbio), e o país atingiu o nível de investment grade em abril de 2008. Pode-se evidenciar, ainda, a manutenção da estabilidade do nível de preços e equilíbrio nas contas públicas - traduzidos em termos de obtenção de superávits primários e administração da dívida pública. Fatores esses que proporcionam um movimento de queda da taxa Selic, passando de $25 \%$ no início do Governo para $10 \%$ em 2010.

A melhoria desses indicadores aliada à expansão da renda da população ${ }^{13}$ e ao emprego formal encorajou os bancos a ampliarem o crédito e aproveitarem a oportunidade que se vislumbrava. Isso evidencia por si só um comportamento pró-cíclico por parte dos bancos brasileiros. Pelo lado externo, os bancos são beneficiados pela ampliação da captação externa. De acordo com Bacen (2014), o volume de recursos externos quase dobra entre 2003 e 2008, passando de $\mathrm{R} \$ 48$ bilhões para $\mathrm{R} \$ 90,8$ bilhões, arrefecendo-se após a crise de 2008, em virtude do racionamento de crédito internacional.

Outro indicador que explicita a mudança de comportamento dos bancos é a queda na taxa Selic. Por ser a taxa básica da economia, sua redução contribui para reduzir o risco de crédito e, principalmente, reduz a atratividade dos títulos públicos, forçando os bancos a reverem sua estratégia de portfólio e política de crédito. Um exemplo dessa nova postura bancária pode ser traduzido pela mudança na composição dos ativos dos bancos. Conforme apontado por Santanna et al. (2009), a participação de títulos e valores mobiliários no ativo bancário passa de $43 \%$ em 2003 para 36\% em 2008, enquanto as operações de crédito passam de $28 \%$ para 32\%. Entre 2008 e 2010, os indicadores permanecem basicamente constantes, porém influenciados pela captação de depósitos à vista e por estímulos criados pelo Banco Central (GUILLEN et al., 2012).

\section{ii) Reformas jurídicas e institucionais:}

Este componente reflete um esforço por parte do Governo e das autoridades monetárias para ampliar a segurança jurídica dos produtos bancários e, dessa forma, ampliar

\footnotetext{
${ }^{13}$ Conforme Neri (2012), 39,6 milhões de pessoas ingressaram na classe C (considerada nova classe média) no Brasil entre 2003 e 2011.
} 
o volume de crédito. Destacam-se aqui as Leis n. 10.820/2003 ("Lei dos Consignados"), 10.931/2004 (Novas regras para o setor imobiliário), 11.101/2005 (Nova Lei de Falências) e outras medidas regulatórias do Bacen.

A Lei 10.820/2003 (regulamentada pelo Decreto 4.961/2004) estabelece normas para o crédito consignado em folha de pagamento. Além das normas gerais, a partir de 2004 essa modalidade foi estendida aos aposentados e pensionistas do INSS. O crédito consignado para PF foi a linha de crédito mais ampliada no período analisado, conforme apontado na seção anterior, sendo o tipo de crédito que apresenta menor risco de inadimplência para os bancos, pois as parcelas da dívida são debitadas diretamente na folha de pagamento. Para a população, essa linha de crédito é atrativa, uma vez que a taxa de juros é, em média, a metade das taxas de juros convencionais ${ }^{14}$, há facilidade na obtenção dos recursos (menor burocracia), além do fato de indivíduos inscritos em cadastros restritivos (SPC e SERASA) terem acesso ao crédito.

O trabalho de Takeda e Bader (2005) apresenta mais dois fatores, para além do marco jurídico, que contribuíram para a ampliação desse tipo de crédito. O primeiro fator refere-se às intervenções do Bacen na redução dos compulsórios sobre depósitos a prazo no final de 2004, ampliando a liquidez dos bancos pequenos e médios, principais agentes desse tipo de crédito na época ${ }^{15}$. O segundo fator decorre do fato de que o Bacen facultou a realização de operações de cessão de créditos. Assim, bancos pequenos vendiam suas carteiras de crédito consignado para bancos maiores. O interesse nesta operação decorria de que o crédito consignado, dado seu baixo risco, não impactava na exigência de capital próprio do banco, dentro dos termos do Acordo de Basileia.

A Lei 10.931/2004 traz inovações importantes que criam um ambiente mais claro e seguro para o mercado de crédito imobiliário, por exemplo, a extensão da modalidade de alienação fiduciária para bens imóveis, a criação da Cédula de Crédito Bancário e de novas opções de captação de recursos para o segmento. Algumas medidas já vinham sendo adotadas desde 1997 com a instituição do Sistema Financeiro Imobiliário, mas precisavam ser referendadas, como foi o caso da necessidade de alteração do Código Civil Brasileiro (Lei 10.406/2002), para incluir a figura da alienação fiduciária.

\footnotetext{
${ }^{14}$ A menor taxa de juros também é explicada pelo aumento da concorrência no setor, por meio da entrada de bancos pequenos e financeiras.

${ }^{15}$ Os bancos pequenos vinham sofrendo perdas de captação após a intervenção do Bacen no Banco Santos dias antes, $11 / 2004$.
} 
A alienação fiduciária é o instrumento que possibilita aos bancos manterem a propriedade do bem financiado em seu nome até a quitação da dívida. Essa situação gera maior segurança jurídica, pois, em caso de inadimplência, o banco pode reaver o bem. Nas operações anteriores a essa lei - e que possuíam como garantia a hipoteca -, os bancos encontravam muitas dificuldades para executar judicialmente contratos inadimplentes em virtude da alegação de "impenhorabilidade do bem de família" (Lei 8.009/1990).

De acordo com Martins et al. (2008), uma segunda mudança dessa lei foi a criação da figura jurídica do patrimônio de afetação, que segrega os recursos captados por construtoras para a execução de projetos imobiliários, preservando da falência da construtora os compradores ou financiadores de imóveis na planta.

Outras inovações dessa lei decorrem da criação de novos instrumentos de captação de recursos, a exemplo das Letras de Crédito Imobiliário (LCI) e da criação de nova modalidade de título de crédito, a Cédula de Crédito Bancário, que, por sua característica de título executivo judicial, torna mais ágil e barata a cobrança de dívidas bancárias na justiça, pois não depende de um processo de conhecimento para sua execução judicial.

A "lei das falências" (Lei n. 11.101/2005 e Lei Complementar n. 117/2005) traz em seu texto novas regras sobre o processo falimentar e sobre reorganização de empresas em dificuldades no Brasil. Em termos de inovação, torna os processos mais ágeis e eficientes, pois permite que sejam efetuadas as transferências de titularidade dos ativos, além de incluir regras de prioridade na falência - por exemplo, que os créditos com garantia real passem na frente dos créditos tributários. Outra melhoria é a criação de condições de recuperação de empresas em dificuldades, neste caso é extinta a figura da concordata e cria-se o instituto da recuperação judicial, que tem como principal característica a elaboração e o oferecimento aos credores de um plano de recuperação. Essa lei era uma reivindicação antiga do setor bancário, pois amplia as garantias para os bancos, em outras palavras, gera maior segurança jurídica.

Com respeito às medidas regulatórias promovidas pelo Bacen, podem ser citadas as Resoluções n. 3.401 e 3.402, ambas de 2006, que visaram a ampliar a competição entre bancos e disciplinar o uso de alguns produtos. A primeira resolução estabeleceu novas regras para a liquidação de financiamentos de Leasing (aprimorou o financiamento de veículos) e para a portabilidade de operações de crédito (viabilizou que correntistas migrem dívidas entre bancos). Além disso, estabeleceu regras para o fornecimento de informações cadastrais de 
clientes entre bancos, a pedido dos clientes (foi um passo em direção ao cadastro positivo e contribuiu para ampliar as informações das instituições financeiras). A segunda resolução dispôs sobre contas salário, dando o direito de o funcionário da empresa escolher em qual banco gostaria de receber seu salário. Ademais, estabeleceu regras para este tipo de contas, como custos de manutenção e tipo de movimentação financeira.

Ainda em âmbito do Banco Central, houve a implementação e aperfeiçoamento do Sistema de Informações de Crédito (SCR) em julho de 2004. Esse Sistema reúne informações mais detalhadas de operações de crédito possuídas por indivíduos em todo o sistema financeiro e disponibiliza tais informações no setor, elemento que melhora a gestão de risco por parte dos bancos.

\section{iii) Fatores microeconômicos:}

No período sob análise (2003-2010), a estabilidade econômica e o crescimento da renda, evidenciado pelo fenômeno da expansão da classe $C$, impuseram aos bancos a necessidade de rever seu portfólio de aplicação de recursos e tentar capturar esse novo público, resultando em maior competição no setor, apesar da concentração verificada após a crise de 2008. Nesse sentido, o comportamento dos bancos refletiu a influência do ambiente macroeconômico (NERI, 2012).

Uma das principais ações para acessar esse nicho de mercado e para ampliar sua participação (market share) foi a ampliação dos postos de atendimento, traduzida na ampliação do número de agências e convênios com empresas (no sentido de terceirização de serviços bancários básicos). Com relação ao número de agências, houve abertura de cerca de três mil novas agências, passando de 16.781 em 2003 para 19.773 em 2010 (BACEN, 2014). Sob o ponto de vista dos convênios, houve o acordo realizado entre Bradesco e Correios no ano de 2002, a criação do Banco Popular do Brasil pelo Banco do Brasil em 2004 e a disseminação do uso dos correspondentes bancários.

Outra iniciativa é a criação de novos produtos segmentados para cada classe de renda dos clientes (baixa, média e alta renda), como é o caso de contas correntes populares e da criação de agências exclusivas para público de alta renda ${ }^{16}$. Na parte de serviços, houve

\footnotetext{
${ }^{16}$ Este tipo de competição por segmentos já vinha sendo praticada antes de 2003, conforme Carvalho (2007).
} 
ampliação dos convênios para pagamento da folha de salário das empresas, um negócio importante para os bancos, na medida em que amplia seu número de clientes e oportunidades de crédito, principalmente por meio do crédito consignado. Os convênios com lojas de carros usados para financiamento de automóveis também foram uma ação muito utilizada até 2008.

Todas essas ações contribuíram para aumentar a concorrência no setor bancário, que é ampliada à medida que os bancos oficiais (BB e CEF) entram em setores do mercado que até então não atuavam, como é o caso do setor empresarial e rural por parte da CEF, do crédito ao consumidor (veículos) e de seguros por parte do BB. A entrada dos bancos públicos, geralmente, deu-se com estratégias agressivas, por meio da redução de tarifas e taxa de juros (NAPOLITANO, 2009a).

Com a crise de 2008, observa-se uma nova fase na ampliação da concorrência no setor, à proporção que ocorrem novas fusões entre bancos, caso do Itaú e Unibanco em 2008, Santander e ABN Real em 2009, aquisição de alguns bancos estaduais por parte do BB, como Nossa Caixa (11/2008), Banco do Estado do Piauí (BEP) (09/2008) e Banco do Estado de Santa Catarina (BESC) (11/2008), bem como parte do Banco Votorantin (01/2009). A CEF também participa de aquisições, comprando parte do Banco Panamericano (12/2009). Apesar das fusões representarem uma maior concentração no setor, os maiores bancos passam a competir pelos clientes, principalmente na estratégia de absorver o público pertencente à classe C. Alguns exemplos dessa concorrência por clientes estão relacionados à abertura de capital do banco Santander em 2009 com uma captação recorde de R \$ 14,1 bilhões (STEFANO; FOGAÇA, 2009); e às estratégias de aquisição do Bradesco (NAPOLITANO, 2009b).

Destaca-se que, dentro dos três fatores mencionados (estabilidade macroeconômica, reformas jurídicas e institucionais e fatores microeconômicos), há a presença da intervenção do Governo, seja via atuação do Banco Central ou Conselho Monetário Nacional (CMN), seja via intervenção direta no mercado pelos bancos oficiais, conferindo-lhe participação ativa no avanço do crédito no país. Para entender de forma mais específica como se deu essa atuação do Governo no setor bancário, a próxima seção analisa as principais medidas de política adotadas no período. 


\section{A POLÍTICA ECONÔMICA DO GOVERNO LULA NO SETOR BANCÁRIO E O NOVO-DESENVOLVIMENTISMO}

Apesar da intervenção governamental no setor bancário ter sido mais intensa no momento da crise de 2008, pode-se elencar outras ações ao longo de todo o período de governo, como: i) ampliação do crédito imobiliário e de consumo, contribuindo para a redução do déficit do setor habitacional e para o dinamismo da demanda agregada até 2008; ii) atuação na preservação de bancos públicos estaduais e fortalecimento do papel do BNDES; e iii) medidas legais e institucionais que contribuíram para a maior agilidade no crédito e solidez do setor, conforme apontado na seção anterior.

Ao analisar especificamente a atuação na crise financeira de 2008, considera-se um conjunto de três ações primordiais: i) ampliação do crédito direcionado (BNDES e PMCMV); ii) medidas macroprudenciais: redução do compulsório, oferecimento de linhas de redesconto e aquisição de bancos em dificuldades; e iii) direcionamento dos bancos oficiais (BB e CEF) para atingir metas do Governo, em termos de oferta de crédito e taxa de juros diferenciadas. Em virtude dos detalhes dessas ações e das dimensões que elas representaram, optou-se, tanto nesta como na seção anterior, por fazer uma análise de cada uma dessas iniciativas.

\section{i) Ampliação do crédito direcionado}

Conforme exposto na seção 2, a expansão do crédito foi liderada até 2008 pelo crédito livre e pelos bancos privados. Após 2008, os bancos privados tomaram uma postura defensiva e restringiram o volume de crédito, principalmente para micro e pequenas empresas. Nesse momento, a expansão passa a ser liderada pelos bancos oficiais (BNDES, BB e CEF) via crédito direcionado. Conforme exposto na Tabela 1 , o total do crédito direcionado passou de R \$ 418,8 bilhões (10,2\% do PIB) em 2008 para R \$ 589,8 bilhões (14,3\% do PIB) em 2010, sendo uma ampliação de $41 \%$.

A maior participação se dá via BNDES. Conforme Annibal et al. (2009), isso foi resultado da injeção de recursos por parte do Tesouro Nacional no banco, na ordem de R\$ 180 bilhões. Dessa maneira, as operações do BNDES se expandiram de R \$ 185,1 bilhões (6,0\% do PIB) em setembro de 2008 para R $\$ 309,3$ bilhões (9,0\% do PIB) em dezembro de 
$2009^{17}$. Destaca-se que grande parte desses recursos foi direcionada para o setor industrial e de infraestrutura, sendo $27 \%$ alocada para micro e pequenas empresas (SATANNA et al., 2009).

Para Santanna et al. (2009), a atuação do banco foi fundamental para manter a liquidez de empresas e do consumo agregado. Nesse caso, o BNDES atuou de forma complementar ao mercado. A complementaridade das ações do BNDES fica mais evidente quando se verifica que suas operações se mantiveram estáveis de 2003 a 2008, abrindo espaço para os bancos privados. O BNDES só expande suas operações a partir da crise de 2008.

Evidencia-se por sua conduta que o papel assumido pelo BNDES no Governo Lula vai ao encontro de pelo menos dois pressupostos do projeto ND. De um lado, considerando o papel de oferta complementar de crédito, citado no parágrafo anterior, enquadra-se na estratégia de intervenção estatal para atuar no fortalecimento do mercado. Por outro lado, a administração de funding e o direcionamento de recursos para setores estratégicos estão de acordo com a necessidade de fortalecer o setor industrial nacional e formar um sistema de financiamento funcional para alavancar investimentos na economia.

Outra frente importante dentro do crédito direcionado é o lançamento do PMCMV em abril de 2009 com orçamento na ordem de R\$ 60 bilhões e objetivo de criar um milhão de moradias populares (para famílias com renda de até 10 salários mínimos). O esforço realizado pelo PMCMV pode ser evidenciado pelo volume de crédito imobiliário liberado (conforme Tabela 1), passando de um estoque de R\$ 59,7 bi em 2008 para mais R\$ 131 bilhões em 2010 ao final do Governo. Esse Programa foi fundamental para manter a demanda agregada elevada, tendo em vista o forte efeito multiplicador que o setor de construção civil, alvo do crédito, possui (FONSECA et al., 2013) ${ }^{18}$.

Nesse sentido, o PMCMV pode também ser enquadrado em uma estratégia ND na medida em que propiciou expansão de crédito adequado com fundos próprios, buscando promover o desenvolvimento. Em termos de crédito direcionado em geral, Lundberg (2010) conclui que a forma com que se comportou o mercado de crédito no Brasil pós-crise de 2008 reforça a importância do crédito direcionado na economia brasileira, pois, ao garantir a oferta

\footnotetext{
${ }^{17}$ Segundo Lundberg (2010), no ano de 2009, com o desembolso de R $\$ 168,4$ bilhões, o BNDES bate o seu recorde histórico em liberação de crédito.

${ }^{18}$ A CEF principal braço do Governo para a liberação dos recursos iniciou um processo para reduzir a burocracia do financiamento, reduzindo de 250 para 50 normas para liberação, descentralizando a aprovação dos créditos, reduzindo o prazo médio de análise e liberação do crédito de 60 para 45 dias e terceirização de serviços como o recebimento da documentação por construtoras e imobiliárias.
} 
de crédito, possibilitou manter investimentos iniciados antes da crise e a demanda necessária para não frustrar expectativas.

\section{ii) Medidas macroprudenciais}

No rastro da expansão do crédito direcionado, verificou-se a tentativa de manter a solidez do sistema financeiro e assegurar que os bancos mantivessem sua atuação no mercado de crédito. Como principais medidas, destacaram-se a redução da exigência de depósitos compulsórios, o oferecimento de linhas de redesconto e a instituição da garantia especial do Fundo Garantidor de Créditos (FGC).

A redução dos compulsórios ocorreu no período de 24/09/2008 a 13/10/2008, passando de $45 \%$ para $42 \%$ sobre os depósitos à vista e demais reduções sobre depósitos a prazo, interfinanceiro e de poupança. Em complemento à redução dos compulsórios sobre os depósitos a prazo, houve aumento na dedução do valor do depósito, de $\mathrm{R}$ \$ 300 milhões para R \$ 700 milhões, e depois para R\$2,0 bilhões. Além disso, os bancos foram autorizados a utilizar até $40 \%$ desse valor para a aquisição de direitos creditórios no mercado interbancário, limite que foi aumentado para 70\% (TAKEDA; DAWID, 2009).

Esses dois dispositivos garantiram maior fôlego aos bancos pequenos e médios e a estabilidade do SFN. Segundo o estudo de Takeda e Dawid (2009), essas medidas tinham como principal objetivo manter a liquidez de crédito doméstico, tendo em vista a retração do crédito internacional ${ }^{19}$. Essa mudança acabou tendo maior impacto sobre os bancos menores, pois, além da dificuldade das fontes externas, possuíam desvantagem na concorrência com grandes bancos pelos depósitos dos correntistas domésticos, sofrendo, assim, maiores restrições de liquidez. Dessa forma, essas medidas foram fundamentais para manter a liquidez e a estabilidade de SFN, pois garantiram a viabilidade de pequenos bancos.

\section{iii) Atuação de bancos públicos}

Observa-se que o Governo Lula não se absteve de utilizar os seus principais bancos de varejo (BB e CEF) para estimular e direcionar a competição no setor bancário. Além de

\footnotetext{
${ }^{19}$ Uma importante fonte de recursos para os bancos nacionais era a captação no exterior, essa fonte reduziu de R\$ 90,8 bilhões em 2008 para R\$ 54,90 bilhões em 2009.
} 
esses bancos terem liderado políticas públicas importantes do Governo, como o financiamento agrícola e habitacional, esses bancos também lançaram mão de estratégias para ampliar sua participação no setor e regular o mercado. A entrada mais agressiva dos bancos públicos ficou mais evidente após a crise de 2008, quando tais bancos compraram participações de bancos menores em dificuldades - a exemplo do Panamericano pela CEF e do Banco Votorantim pelo BB.

O caso mais emblemático dessa atuação na crise foi a determinação do Governo para que os bancos públicos (BB e CEF) reduzissem suas taxas de juros e ampliassem suas carteiras de crédito (principalmente para micro e pequenas empresas) ${ }^{20}$. Conforme Napolitano (2009a), a partir dessa determinação, BB e CEF ampliaram suas operações de crédito em $30 \%$ e reduziram suas tarifas em $20 \%$.

Deve-se registrar ainda que a incorporação dos bancos Nossa Caixa, BESC e BEP pelo BB denota o perfil de garantir que essas instituições não fossem privatizadas. Essa estratégia visou, em primeiro lugar - principalmente no caso da Nossa Caixa - à expansão do banco para fazer frente ao crescimento dos bancos privados e reforçar o papel estratégico dado pelo governo aos bancos públicos, este último mais específico ao caso do BESC ${ }^{21}$.

A atuação dos bancos oficiais evidencia uma política intervencionista do Governo buscando manter a estabilidade macroeconômica no período. A forma de atuação dos bancos públicos toma uma postura que Vidotto (2005) já vinha destacando como "intervenção eficiente", em virtude de que tais bancos não apenas se vergam aos interesses do Estado (em algumas ocasiões espúrias), mas estão sob pressão do mercado, e, portanto, possuem uma gestão agressiva do ponto de vista privado.

Ao analisar o conjunto de medidas adotadas pelo Governo Lula no setor bancário à luz da literatura de ND, são observados alguns pontos de aderência. O primeiro refere que a forma de condução dos bancos públicos de varejo (BB e CEF) pelo Governo Lula se aproxima muito da posição ND quando defende uma estabilidade macroeconômica mais ampla, não apenas em termos de estabilidade de preços, mas estabilidade que leve em consideração a manutenção de emprego e a demanda efetiva.

\footnotetext{
${ }^{20}$ No caso do BB, segundo Prates e Freitas (2013), o governo impôs a troca de presidente do banco, para garantir o desempenho das funções de banco público no momento de crise.

${ }^{21}$ O BESC foi federalizado em 10/2000, quando são injetados R 780 milhões e transferidos $67 \%$ das ações do Besc para a União. O objetivo inicial da federalização era sanear o banco para depois privatizá-lo.
} 
Um segundo ponto de aderência ao ND decorre do fortalecimento mútuo dos ramos privado e estatal no setor bancário. Isso porque, ao se manter os bancos públicos atuando de forma anticíclica no setor financeiro - contribuindo para estimular a concorrência nas atividades econômicas, mas sem descuidar de sua estabilidade (segurança bancária) -, é possível manter a liquidez das instituições financeiras (como é o caso da compra de carteira de créditos de bancos de pequeno porte, apontado nas medidas de regulação macroprudencial) e a estabilidade da oferta de crédito na economia.

\section{CONSIDERAÇÕES FINAIS}

O presente trabalho fez um cotejo do setor bancário para o período que compreende o Governo Lula, objetivando analisar o comportamento do crédito, os fatores que promoveram tal desempenho e avaliar em que medida esses fatores se coadunam com as proposições ND. Ao percorrer as quatro partes anteriores deste texto, pode-se evidenciar que houve três fatores principais que contribuíram para a expansão de crédito brasileiro.

O primeiro está relacionado com a estabilidade macroeconômica, que proporcionou, por um lado, que os bancos se encorajassem na ampliação do crédito, e, por outro lado, acabaram forçados a alterar seu portfólio em virtude da queda da taxa Selic. O segundo fator refere-se às reformas jurídicas e institucionais, que contemplam um conjunto de inovações legais que ampliam a segurança jurídica e impõem regras claras sobre a concessão de crédito e garantias. O terceiro relaciona-se com alterações no seio do setor bancário, como inovação e competição, o que se denominou neste trabalho como fatores microeconômicos. Destacase que todos esses fatores sofreram a influência da ação de políticas econômicas do governo.

Avaliar as ações do Governo Lula no setor bancário, que contribuíram para elevar sua solidez e estimular a oferta de crédito, permite indicar que essas ações se aproximam das proposições feitas ao sistema financeiro pela literatura de ND. Dentre tais ações, destacaramse: i) ampliação do crédito imobiliário e de consumo até 2008; ii) atuação na preservação e fortalecimento de bancos públicos; iii) medidas legais e institucionais que contribuíram para a maior agilidade no crédito e solidez do setor; e iv) medidas contracíclicas para estabilizar o setor em meio à crise financeira de 2008, como: ampliação do crédito direcionado; medidas macroprudenciais; e direcionamento dos bancos oficiais (BB e CEF) para atingir metas do Governo em termos de oferta de crédito e taxas de juros diferenciadas. 
Pode-se evidenciar que todas essas políticas estão alinhadas à concepção e ao receituário ND de "sistema financeiro funcional", que consistiria em um sistema financeiro sólido e seguro, com capacidade de financiar o investimento produtivo do país, com ênfase no fortalecimento de um sistema de financiamento público capaz de contribuir para promover o projeto de desenvolvimento nacional.

Nesse sentido, mesmo não sendo de forma intencional, as medidas adotadas pelo Governo Lula se aproximam muito das proposições feitas por Carvalho (2005) para ampliar a eficiência do SFB em termos de maior volume de recursos para investimento, redução do custo do capital e acesso das classes de renda mais baixa a produtos e serviços financeiros, conforme ficou demonstrado no trabalho. O método para atingir tal eficiência também se aproxima desse receituário, que são os incentivos de mercado e a intervenção regulatória.

Apesar dos avanços no setor e da realização de políticas afeitas ao ND, deve-se ter em mente que o país tem ainda um longo caminho a seguir no rumo de seu desenvolvimento financeiro e de um SFB funcional. As principais restrições no setor encontram-se na ainda baixa relação crédito/PIB se comparado com outros países em desenvolvimento, na existência de insegurança jurídica e no fato de que a competição bancária que se ensaiou no Brasil nos anos 2000 ainda não se traduziu em queda mais expressiva do spread bancário. Nesse cenário, a implementação de políticas de cunho ND no setor bancário pelos próximos governos poderia contribuir para essa evolução.

\section{REFERÊNCIAS}

ANNIBAL, C.; LUNDBERG, E.; KOYAMA, S. M. Crise de 2008 e as mudanças no mercado de crédito. Relatório de Economia Bancária e Crédito, p. 37-52, Brasília: Bacen, 2009.

BANCO CENTRAL DO BRASIL (BACEN). Relatório de economia bancária e crédito. Disponível

em: https://www.bcb.gov.br/publicacoes/relatorioeconomiabancaria/cronologicos. Vários anos. Acesso em: 03 jan. 2021.

BANCO CENTRAL DO BRASIL (BACEN). Sistema de Informações do Banco Central (SISBACEN). Disponível em: https://www.bcb.gov.br/acessoinformacao/sisbacen. Acesso em: 03 jan. 2021.

BANCO MUNDIAL (BIRD). Global financial development report 2013. Disponível em: https://www.worldbank.org/en/webarchives/archive?url=http\%3A\%2F\%2Fweb.worldbank. 
org\%2Farchive\%2Fwebsite01597\%2FWEB\%2F0 CONTE.HTM\&mdk=913598646.

Acesso em: 04 jan. 2021.

BARBOSA, N.; SOUZA, J. A. P. A inflexão do governo Lula: política econômica, crescimento e distribuição de renda. 2010. Disponível em: http://nodocuments.files.wordpress.com/2010/03/barbosa-nelson-souza-jose-antoniopereira-de-a-inflexao-do-governo-lula-politica-economica-crescimento-e-distribuicao-derenda.pdf. Acesso: 04 jan. 2021.

BIELSCHOWSKY, R. Pensamento econômico brasileiro: o ciclo ideológico do desenvolvimento. Rio de Janeiro: IPEA/INPES, 1988.

BRESSER-PEREIRA, L.C. Desenvolvimento e crise no Brasil. 5. ed. São Paulo: Ed. 34, 2003.

BRESSER-PEREIRA, L.C. Novo-desenvolvimentismo. Caderno Dinheiro. Folha de São Paulo, 19/09/2004.

BRESSER-PEREIRA, L.C. O novo-desenvolvimentismo e a ortodoxia convencional. São Paulo em Perspectiva, v. 20, n. 3, pp. 5-24, 2006.

BRESSER-PEREIRA， L.C.; OREIRO， J. L.; MARCONI， N. Macroeconomia desenvolvimentista: teoria e política econômica do novo desenvolvimentismo. RJ: Campus, 2016.

CARVALHO, F. J. C. de. O sistema financeiro brasileiro: a modernização necessária. In: SICSÚ, J.; PAULA, L. F. de; e MICHEL, R. Novo-Desenvolvimentismo: um Projeto Nacional de Crescimento com Eqüidade Social. RJ: Fundação Konrad Adenauer, 2005.

CARVALHO, F. J. C. de. Estrutura e padrões de competição no sistema bancário brasileiro: uma hipótese para investigação e alguma evidência preliminar. In: PAULA, L. F. de; OREIRO, J. L. Sistema financeiro: uma análise do setor bancário brasileiro. RJ: Elsevier, 2007.

FONSECA, P. C. D.; CUNHA, A. M.; BICHARA, J. da S. O Brasil na era Lula: retorno ao desenvolvimentismo? Nova Economia, v. 23, n. 2, pp. 403-428, maio-agosto/2013.

GUILLÉN, O. T. C.; VICENTE, J. V. M.; MORAES, C. O. Análise do comportamento dos bancos brasileiros pré e pós-crise subprime. Relatório de Economia Bancária e Crédito, pp. 53-64, Brasília: Bacen, 2012.

INSTITUTO DE PESQUISA ECONÔMICA APLICADA (IPEA). Dados macroeconômicos. Disponível em: http://www.ipeadata.gov.br/Default.aspx. Acesso em: 04 jan. 2021.

LUNDBERG, E. L. Bancos oficiais e crédito direcionado: o que diferencia o mercado de crédito brasileiro? Relatório de Economia Bancária e Crédito, p. 41-67, Brasília: Bacen, 2010. 
MARTINS, B. S.; LUNDBERG, E. L.; TAKEDA, T. Crédito habitacional no Brasil: aperfeiçoamentos institucionais e avaliação da evolução recente. Relatório de Economia Bancária e Crédito, p. 79-103, Brasília: Banco Central, 2008.

MOLLO, M. R. L.; FONSECA, P. C. D. Desenvolvimentismo e Novo-Desenvolvimentismo: raízes teóricas e precisões conceituais. Economia Política, vol. 33, n. 2 (131), pp. 222-239, abril-junho, 2013.

MORAIS, L.; SAAD-FILHO, A. Da economia política à política econômica: o novodesenvolvimentismo e o governo Lula. Economia Política. Vol. 32, n.4 (124), out-dez, 2011.

NAPOLITANO, G. A mão visível do Estado. Seção Finanças. Exame, ano 43, n. 17, ed. 951, p. 156-158, 09/09/2009. 2009a.

NAPOLITANO, G. Reforma na Cidade de Deus. Seção Finanças. Exame, ano 43, n. 14, ed. 948, p. 90-92, 29/07/2009. 2009b.

NERI, M. A nova classe média: o lado brilhante da pirâmide. São Paulo: Saraiva, 2012.

PAULA, L.F. R. de. Tamanho, dimensão e concentração do sistema bancário no contexto de alta e baixa inflação no Brasil. Revista Nova Economia, v.8, n.1, p. 87-116, jul-dez/1998.

PRATES, D. M.; FREITAS, M. C. P. Crédito bancário corporativo no Brasil: evolução recente e perspectivas. Economia Política, vol. 33, n. 2 (131), pp. 322-340, abril-jun/2013.

ROCHA, F. A. S. Evolução e concentração bancária no Brasil (1994-2000). Notas Técnicas do Banco Central, n. 11. Nov/2001.

SALVIANO JR. C. Bancos estaduais: dos problemas crônicos ao PROES. Brasília: Banco Central do Brasil, 2004. 150p.

SANTANNA, A. A.; BORÇA JUNIOR, G. R.; ARAUJO, P. Q. de. Mercado de crédito no Brasil: evolução recente e o papel do BNDES (2004-2008). In: FERREIRA, F. M. R.; MEIRELLES, B. B. (Orgs). Ensaios sobre economia financeira. Rio de Janeiro: BNDES, 2009.

SICSÚ, J.; PAULA, L. F. de; MICHEL, R. Novo-Desenvolvimentismo: um Projeto Nacional de Crescimento com Eqüidade Social. Barueri-SP: Manole e RJ: Fundação Konrad Adenauer, 2005.

SICSÚ, J.; PAULA, L. F. de; MICHEL, R. Por que novo-desenvolvimentismo? Economia Política. Vol. 27, n.4 (108), outubro-dezembro, 2007.

STEFANO, F.; FOGAÇA G. Recorde mundial, e agora? Seção Bancos. Exame, ano 43, n. 20, ed. 954 , p. $20-27,21 / 10 / 2009$. 
SOARES, R. P. Evolução do crédito de 1994 a 1999: uma explicação. Textos para Discussão do IPEA, n. 808, jul/2001.

SOBRINHO, N. F. S. Uma avaliação do canal de crédito no Brasil. $25^{\circ}$ Prêmio BNDES de Economia, Rio de Janeiro: BNDES, 2003.

TAKEDA, T.; DAWID, P. E. Liberação de compulsórios, crédito bancário e estabilidade financeira no Brasil. Relatório de Economia Bancária, p. 53-68, Brasília: Bacen, 2009.

TAKEDA, T.; BADER, F. L. C. Consignação em folha de pagamento: fatores da impulsão do crédito. Relatório de Economia Bancária, p. 69-87, Brasília: Banco Central, 2005.

TAVARES, M. C. Da Substituição de Importações ao Capitalismo Financeiro. 11. ed. Rio de Janeiro: Zahar, 1983.

VIDOTTO, C. A. Reforma dos bancos federais brasileiros: programa, base doutrinária e afinidades teóricas. Economia e Sociedade, Campinas, v. 14, n. 1 (24), p. 57-84, $\mathrm{jan} / \mathrm{jun} / 2005$. 